\title{
Homero: oralidade, tradição e história
}

\section{Gustavo Junqueira Duarte Oliveira*}

\begin{abstract}
Resumo: Este artigo pretende discutir a questão da Abstract: The discussion in this paper concerns the oralidade nos poemas homéricos e suas implicações problem of orality in the Homeric poems, and the para o estudo da história, com ênfase especial para a implications of this problem to the studies of History. questão da tradição. Uma breve revisão bibliográfica A special emphasis is given to the problem of tradition. acerca dos problemas da composição oral será A bibliographic presentation will be made concerning apresentada, seguida de considerações acerca da the problems of oral composition, followed by validade do uso de tais fontes para o estudo da história. considerations about the validity of such sources to the As questões apresentadas são as seguintes: é possível study of History. The questions presented will be the que a sociedade descrita nos poemas seja o reflexo de following: is it possible that the society described in the alguma sociedade histórica que possa ser estudada pela poems was the reflex of a historical society that could análise das epopéias em questão? Se os poemas são be studied by the analysis of those epics? If the poems válidos como fontes históricas, são válidos para qual are valid as historical sources, for which period are período? O período micênico, que tenta retratar? they valid? The one they deal with (the Micenic past), Aquele de sua produção ou o de sua fixação como the one of their production or the one of their textos escritos? A solução proposta é considerar os establishment as written texts? The solution proposed textos como veículos de uma tradição que tem uma is to consider the texts as vehicles of a tradition that has validade histórica por transmitir valores ideais. a historical validity because it transmits ideal values.
\end{abstract}

Palavras-chave: Homero; oralidade; tradição; história. Keywords: Homer, orality, tradition, History

Uma das maiores contribuições para os estudos homéricos no século $\mathrm{XX}$ foi, sem dúvida, a investigação concebida e conduzida inicialmente por Milman Parry, continuada por seu discípulo Albert Bates Lord, acerca da técnica oral tradicional pela qual os poemas épicos são compostos, aplicada principalmente à Ilíada e à Odisséia. A proposta do presente trabalho é refletir acerca de aspectos dessa teoria, analisando a perspectiva de alguns autores para, por fim, pensar em maneiras de utilizar os poemas homéricos como fontes históricas.

O problema a ser trabalhado se dá em função das seguintes dificuldades: é possível que a sociedade descrita nos poemas seja o reflexo de alguma sociedade histórica que possa ser estudada pela análise das epopéias em questão? A qual período corresponderia essa sociedade? Ao período micênico, no qual a trama se desenvolve? Ou seria ao período em que os poemas foram produzidos? Qual seria esse período? A composição dos poemas envolve a sua imediata fixação como texto escrito? Em outras palavras, se são válidos como fontes

\footnotetext{
* O autor é bacharel em História pela Universidade Federal de Minas Gerais e mestrando do departamento de História Social da Universidade de São Paulo. É bolsista da Fapesp. Email: gustavojdo@gmail.com
} 
históricas, são válidos para o período do qual tentam tratar, para o período em que foram produzidos ou para o período em que foram fixados como textos escritos?

Tais dificuldades são apresentadas em função do próprio desenvolvimento desse ramo dos estudos homéricos. Esse conjunto de dificuldades impõe ao historiador que deseja trabalhar com os poemas do ponto de vista da história uma tomada de posição. Uma vez que atualmente a Ilíada e a Odisséia são amplamente aceitas como apresentando um caráter oral e tradicional, embora isso não seja uma unanimidade entre os homeristas e permita uma variedade muito grande de interpretações, faz-se necessário ao historiador tecer algumas considerações a esse respeito.

Vale desde já deixar explicitado que a história dos manuscritos desde a antiguidade, passando pela idade média até os dias de hoje, não entrará na análise proposta, nem tampouco serão utilizados conceitos nem métodos da história oral. A análise técnica de fórmulas e temas, bem como a crítica literária, também estarão, em geral, fora da proposta deste trabalho.

É preciso, portanto, fazer uma breve exposição acerca de alguns elementos centrais da chamada teoria oral, no intuito de identificar a natureza dos textos, para em seguida serem levantadas propostas de como tais fontes podem ser utilizadas no estudo da história.

Antes mesmo de partir para a Iugoslávia para conduzir pesquisas de campo no interior de uma tradição oral viva, Milman Parry já havia começado a se preocupar com o caráter oral da poesia homérica. Ele já havia se dedicado ao problema das fórmulas em Homero ${ }^{1}$, demonstrando um caráter formular e tradicional na Ilíada e na Odisséia, propondo uma leitura pela qual relações métricas justificam a utilização de um nome acrescido de um determinado epíteto tradicional. Em dois estudos produzidos nos anos trinta, também anteriores a suas pesquisas de campo, PARRY (1930 e 1932) já se propõe a analisar a técnica oral da construção de versos na poesia épica, com ênfase no estudo comparativo, aplicada a Homero.

Sua proposta no primeiro desses estudos é a de utilizar um método histórico de crítica próprio, no qual a análise do texto é o ponto fundamental, para que se consiga encontrar elementos que demonstrem uma nova concepção de arte poética (cf. PARRY, 1930, p.76). PARRY (1930) se afasta, portanto, de uma análise literária baseada em idéias religiosas, culturais, sociais ou históricas, buscando repostas na maneira como o estilo homérico é criado.

Seu primeiro passo é tomar os poemas homéricos como sendo de estilo tradicional e compostos oralmente. A partir daí, Milman Parry busca compreender como esses elementos

\footnotetext{
${ }^{1}$ A tradução de L'Épithète traditionelle dans Homère encontra-se no primeiro capítulo de The Making of the Homeric Verse, editado por Adam Parry em 1971.
} 
diferem dos estilos e das formas escritas de criação poética. Esse autor entende que no estilo tradicional, no qual o poeta só expressa idéias para aquilo que ele tem maneiras fixas de expressão (cf. PARRY, 1930, p.78), aquele que compõe faz parte da tradição, pertencendo à cultura de onde vem. É um estilo oral e profundamente regrado, no qual, mesmo que um poeta faça uma contribuição original, ela deve ser aceita pelo grupo de poetas e ouvintes e ser assim incorporada à tradição.

Para a argumentação de PARRY (1930) é irrelevante discutir a antiguidade da escrita grega alfabética e sua utilização ou não nos tempos de Homero. O que importa é a busca da resposta à seguinte questão: mesmo estando os textos existentes hoje escritos, um fato histórico indiscutível, os poemas homéricos estão em um estilo escrito ou oral?

Se for conduzido um estudo sistematizado do verso homérico comparando-o àquilo que se sabe ter sido composto em um estilo individual escrito de um único poeta, e assim for encontrada uma diferença que impede a própria comparação, para PARRY (1930) ficará constatado que os poemas homéricos não foram produzidos da mesma maneira com que os poetas posteriores produziram. E ele afirma que esse problema só será resolvido aceitando que se trata de versos compostos inteiramente em um estilo tradicional e adaptado à versificação oral, diferente da escrita. Para mostrar que os poemas homéricos são de fato orais, PARRY (1930) se utiliza de um método com critérios bem definidos, e em geral bem aceitos $^{2}$. Portanto, PARRY (1930) investiga no primeiro artigo essas diferenças, apontando as especificidades do verso homérico diante de autores que são sabidamente escritores.

Mais algumas considerações de PARRY (1930) são importantes para o presente trabalho. Em primeiro lugar, a própria noção de autoria deve ser avaliada. Mesmo que um poeta tenha criado fórmulas ${ }^{3}$, esse fato não é por si só relevante, pois, como já foi dito, a sua incorporação à linguagem tradicional é o que importa. E essa incorporação só se dá caso observe regras rígidas, pelas quais as fórmulas sejam facilmente inseridas na métrica. Além disso, a quantidade e a qualidade das fórmulas impedem a conclusão de que os poemas sejam fruto do trabalho de um homem só. Mas tal afirmação precisa ser bem explicada, pois PARRY (1930) está se referindo justamente à questão da tradição. Essa tradição, no estágio em que está apresentada nos poemas homéricos, implicaria uma formação de muitos séculos, o que é indicado por sua qualidade e profundidade, e pela sobrevivência de termos arcaizantes

\footnotetext{
2 Trata-se de uma análise formular, de temas e de enjambments, utilizada também em LORD (1960) e NOTOPOULOS (1964).

${ }^{3}$ Uma fórmula é definida por PARRY (1930, p. 80) como um grupo de palavras usado regularmente em uma mesma condição métrica para expressar uma determinada idéia essencial.
} 
e de vários dialetos (indicação de abrangência geográfica), misturados com termos artificiais e outros da linguagem comum (cf. PARRY, 1930, p. 136). O aprendizado dessas fórmulas é impossível de ser adquirido pela leitura de textos tradicionais, pois o que está em questão não é só a facilidade da utilização das fórmulas, mas sim uma necessidade para a composição rápida em performance. E quando o poeta pode, ele modificará uma fórmula conhecida para expressar algo com um significado novo, sem saber diferenciar qual é a fórmula e qual é a criação ${ }^{4}$. O sistema de criação de fórmulas funciona assim. E caso as novas fórmulas sejam adotadas por outros poetas, estando ajustadas à composição tradicional, elas entram para a tradição (cf. PARRY, 1930, p. 147).

O segundo artigo de PARRY a ser aqui tratado, Studies in the Epic Technique of Oral Verse-Making II. The Homeric Language as the Language of an Oral Poetry, de 1932, trata mais especificamente da língua dos poemas homéricos. Em linhas gerais, ele propõe que essa língua poética seria dividida entre os poetas e seus ouvintes, existindo em função do tipo de verso em questão e adaptada à sua métrica e à composição oral. Seu desenvolvimento é o trabalho não de um homem ou um grupo, pois ela é formada por muitos poetas durante várias gerações. É uma língua que não é a do dia-a-dia, pois ela soa arcaica, artificial e maravilhosa, misteriosa para o público.

Uma de suas proposições é de extrema relevância: um poeta neste contexto é melhor do que outro não porque consegue expressar melhor seus pensamentos, mas porque é mais hábil para usar a tradição. Ele se esforça não para criar um novo ideal na poesia, mas para alcançar aquilo que todos sabem ser o melhor (cf. PARRY, 1932, p. 13).

Para PARRY (1932), a qualidade dos poemas homéricos é muito superior à de outras poesias orais. Isto sugere que, no caso grego, nos períodos em que essa tradição oral estava viva, seus poetas formavam uma classe mais profissional e especializada do que é o normal para outras culturas com tradições orais. E PARRY (1932) questiona: estes poemas teriam sido escritos na época de Homero ou decorados por recitadores profissionais? Teriam sido passados por manuscritos entre cantores que ainda eram criativos, mas que também cantavam os cantos mais famosos? Para ele, nossos manuscritos não são vindos diretamente de Homero, mas variantes dentro de uma tradição oral (cf. PARRY, 1932, p. 47). Os poemas estariam dentro de uma longa tradição, que continuou por alguns séculos, pois PARRY (1932) considera que alguns hinos também apresentam características orais e estariam dentro de uma

\footnotetext{
${ }^{4}$ Este argumento foi mais desenvolvido por LORD (1960), que afirma tratar-se mais de um mecanismo de expressão formular, que envolve uma criação baseada em fórmulas conhecidas, do que de uma simples utilização de fórmulas decoradas. Tal argumento será mais explicado adiante.
} 
mesma e longa tradição. Semelhante é o argumento de James A. Notopoulos (1964). Para ele, a poesia oral sobreviveu à introdução da escrita, sendo uma tradição que teve origens nos tempos micênicos e durou até o início do século V a.C (cf. NOTOPOULOS, 1964, p. 20), algo que será melhor discutido adiante.

Todas essas questões e algumas outras que serão exploradas mais adiante foram levantadas por Parry antes mesmo de ele ter se engajado em pesquisas de campo na Iugoslávia. No entanto, a morte prematura do autor impediu que ele desenvolvesse plenamente a sua teoria, após essas pesquisas terem sido realizadas. A tarefa foi prosseguida, assim, pelo seu discípulo, Albert Bates Lord.

Alguns elementos adiantados por PARRY (1930 e 1932) foram confirmados pelas pesquisas de campo, e algumas formulações mais completas foram desenvolvidas por LORD no livro The Singer of Tales, de 1960. Assim, alguns conceitos e temas desse livro merecem algum destaque, e têm lugar importante nesta discussão. A questão da performance é central no livro. LORD (1960) esforça-se para deixar claro que cada performance é única e leva a marca de seu do poeta/cantor. Mas não se trata de uma originalidade ilimitada, principalmente se comparada com textos escritos, pois está firmemente presa à tradição (cf. LORD, 1960, p.4).

Em uma breve definição do que seria a canção oral épica, LORD (1960) diz tratar-se de um tipo de narrativa poética, desenvolvida por gerações de cantores que não sabiam escrever. O processo consiste na formação de linhas ou partes de linhas métricas, por meio de fórmulas ou de expressões formulares, e na construção de canções pelo uso de temas recorrentes. O aprendizado oral, a composição e a transmissão quase se misturam, tornando-se facetas de um mesmo processo. Não se trata somente de uma performance, mas de uma composição durante a performance. O poeta que canta não é apenas um veículo para a tradição, pois também a cria ao cantar, uma vez que é um poeta criativo. Um mero recitador não é um poeta oral.

O poeta/cantor compõe por um processo no qual deve colocar seus pensamentos dentro de uma rígida norma rítmica e métrica, e deve fazer isso na composição em performance, rapidamente. Por isso as fórmulas são essenciais para esse tipo de composição. Durante seu treinamento, o poeta aprende um conjunto de fórmulas, provavelmente de outros cantores, os que ele mais observou, e as guarda. Esse não é, no entanto, um mero processo mnemônico. A partir dessas fórmulas, ele cria inúmeras outras expressões formulares para expressar o que deseja dizer. Ele aprende, portanto, não somente fórmulas, temas e poemas, mas uma arte poética e uma técnica de composição formular. Sua verdadeira arte consiste em 
criar frases adaptadas, no nível da formação de linhas, e a facilidade com que faz isso, e não sua memória de fórmulas fixas, é o que o torna um cantor habilidoso que compõe em performance (cf. LORD, 1960, p. 43). Alguém que aprende somente frases feitas e fórmulas não necessariamente se torna um poeta/cantor, pois o que deve ser aprendido é o sistema de criação de fórmulas. E quando alguém se torna um poeta/cantor completo, transita dentro da tradição, conhecendo temas e fórmulas o suficiente, criando outros a partir desses e podendo cantar qualquer canção que ouvir, aumentando-as ou diminuindo-as como quiser. A relação do cantor com as fórmulas não é muito diferente da que tem com os temas, pois estes não são conjuntos fixos de palavras, mas de idéias.

Mesmo reconhecendo que as variações existem e são notáveis, LORD (1960) afirma que o que realmente importa para os poetas/cantores é manter a tradição, e não mudá-la. Quando cantam versões diferentes, os bardos iugoslavos dizem cantar a mesma canção da mesma maneira, pois tentam colocar nela todos os elementos de uma determinada estória.

Em função das constatações acima, LORD (1960) acredita poder afirmar que não existe nada nesse tipo de construção poética que não seja formular, estando dentro desse sistema de criação e reprodução de fórmulas (cf. LORD, 1960, p. 47).

Divergências em textos antigos podem ser em função de sua natureza oral, que como já foi dito, apresenta um grande número de variações dentro de uma mesma canção. Não necessariamente essas variações são fruto de modificações propositais de outros cantores ou ação de escribas, e esse pode muito bem ser o caso dos textos homéricos.

LORD (1960) chega a questionar o que é a canção, em função da fluidez entre versões diferentes. Para o cantor, o que importa é manter a essência de uma determinada história, e não manter um texto fixo, palavra por palavra. Mudar uma canção, para ele, seria mudar a sua essência, e por isso considera que canta, quando quer, sempre a mesma canção, independentemente do fato de mudar as palavras. Cada performance é uma recriação.

A poesia oral teria, portanto, dois conceitos do que seria canção: o primeiro se refere ao tema geral da canção, seu título; o segundo se refere a uma performance específica desta canção. A dificuldade que o observador que não está inserido em uma tradição oral viva encontra vem do fato de que, em geral, ele não está acostumado com textos que sejam fluidos. Existe sempre uma busca por um texto original, o que LORD (1960) afirma não fazer sentido para esse tipo de tradição, e sugere que essa busca seja abandonada, também para o caso de Homero (cf. LORD 1960, p. 100). O que deve ser compreendido é o que muda e o que se mantém estável dentro de uma tradição, e o porquê desses processos. 
Um outro elemento importante levantado por LORD (1960), e essencial para a discussão da difusão dos textos homéricos, é o problema da relação dessas tradições com a escrita. Abreviando seus argumentos, LORD (1960) põe sérias dúvidas de que um Homero poderia ser um cantor semi-letrado, pois a qualidade dos poemas impede que tenham sido escritos por alguém que não tivesse pleno domínio de uma das técnicas. Em geral, suas observações o fazem concluir que cantores/poetas iletrados que aprendem a escrever e põem no papel suas canções apresentam resultados decepcionantes, por abandonarem a técnica tradicional em função de elementos novos, provenientes da cultura letrada ${ }^{5}$.

A possibilidade que considera mais provável, e que desenvolveu em uma forma mais completa posteriormente (cf. LORD, 1991, p.44), é a de que esses poemas tenham sido ditados. Primeiramente, LORD (1991) não tem dúvida de que os poemas foram compostos oralmente a partir da técnica tradicional. Para ele, a transcrição durante a performance por si é muito difícil de ser alcançada. E sua própria experiência lhe permitiu observar que no momento em que o poeta/cantor dita seus poemas, apesar de ser um momento diferente, no qual inicialmente o poeta se sente incomodado em função do ritmo mais lento, ele se depara com uma situação nova. Ele tem liberdade para ornamentar e expandir seu poema ao máximo, não tendo que se preocupar com o tempo e tendo uma platéia absolutamente estável e favorável. Além disso, tem a possibilidade de pensar e elaborar melhor sua composição, pois deve esperar o escriba anotar o que foi dito.

O impulso para pôr as obras em forma escrita, no caso de Homero, teria sido, portanto, exterior ao poeta, ou poetas. Os dois poemas teriam sido coletados por meio de sessões em que foram ditados a um escriba (cf. LORD, 1991, p.44). LORD (1991) vê nos poemas homéricos todas as marcas de um texto ditado. Ele inclusive chega a cogitar que possa ter sido um único poeta, Homero, a ter ditado os dois poemas, e data esse acontecimento como tendo se passado provavelmente em meados do século VIII a.C.

Por fim, nada na prática de um poeta oral faz necessária a presença da escrita. A própria noção de um texto fixo é inexistente, e por isso não existe o desejo de alcançá-lo. Mas Lord faz essa concessão à intervenção da técnica escrita para o caso de Homero justamente em função do fato de que os poemas existem hoje, e desde muito tempo, em uma forma escrita.

\footnotetext{
${ }^{5}$ Adam Parry critica essa concepção de Lord, afirmando que a contaminação sofrida pelo poeta que aprende a escrever é oriunda da cultura letrada, no caso da Iugoslávia, e não da própria técnica da escrita. Para Homero, a tecnologia da escrita seria nova e, se um poeta aprendesse a escrever nessa época, não sofreria interferência de outros textos, não deixando de recorrer, portanto, a uma técnica exclusivamente tradicional de composição (PARRY, 1989, p. 137).
} 
PARRY $(1930,1932)$ e LORD (1960) propuseram, portanto, de maneira definitiva, a questão da oralidade e as particularidades que o método de composição oral apresenta. A partir deles, ou mesmo paralelamente a eles, muitos outros estudiosos voltaram seus esforços para tais problemas, e alguns deles serão na seqüência o objeto desta breve exposição.

G. S. Kirk tentou abordar a questão de maneira ampla, escrevendo um livro centrado nos poemas homéricos, The Songs of Homer, de 1962, publicado em uma versão revisada e ligeiramente reduzida pelo título de Homer and the Epic, em 1965. O fato de os poemas homéricos terem sidos compostos oralmente é aceito com convicção nesse livro. Esse e outros pontos convergentes ao que já foi apontado anteriormente não serão reapresentados. No entanto, o autor se esforça em demonstrar alguns limites da comparação entre esses poemas com a tradição iugoslava. A principal dessas críticas se dá em função da diferença de qualidade entre as tradições. Para ele, os poemas homéricos estão em um patamar muito mais elevado de qualidade, fato que por si só já basta para demonstrar que as situações não são as mesmas. Os bardos iugoslavos seriam artistas iletrados marginais dentro uma cultura predominantemente letrada. Muito diferentes dos bardos gregos, virtuosos na sua arte, e figuras centrais de uma tradição cultural.

A diferença apresentada é fundamental para a sequiência de seu argumento. KIRK (1965) apresenta um quadro evolutivo no qual marca diferentes estágios do desenvolvimento da poesia oral tradicional (cf. KIRK, 1965, p. 27-28). O primeiro estágio é o originativo, no qual a poesia narrativa em verso é diferenciada das sagas, prosas e poemas ocasionais do mundo ordinário. Nesse período o corpo dos poemas começa a ser delimitado, sendo baseado tanto em eventos históricos quanto em um passado mítico. No caso da poesia heróica oral tradicional grega, esse período corresponde ao contexto micênico, no qual KIRK (1965) acredita que fatos históricos inspiraram a produção de canções épicas, entre eles a guerra de Tróia. O segundo estágio é o criativo, no qual as técnicas mnemônicas e de improvisação são refinadas. O repertório é aprendido, expandido e criado (improvisado), dentro de uma linguagem já tradicional com temas e fórmulas, por geração após geração de poetas/cantores. Os cantores principais da Ilíada e da Odisséia estariam nesse estágio. O terceiro estágio é o reprodutivo, no qual a técnica oral é usada para memorização e a transposição, e é assim que ele descreve o processo de composição dos cantores iugoslavos, que estariam nesse estágio. $\mathrm{O}$ quarto estágio é o degenerativo, no qual há muita interferência da escrita, a técnica de composição oral declina e dá espaço para a recitação pura. Esse seria o período em que estariam os rapsodos gregos. 
O quadro de Kirk parece artificial e não comprovável. O que é interessante nele é a constatação de que Homero estaria num estágio em que a tradição viva seria oriunda de um passado que remonta a várias gerações passadas. Sua tentativa de retraçar, para o caso grego, qual seria esse período também é digna de nota. Mas fora isso, a interpretação dele de que os bardos iugoslavos seriam meramente recitadores parece ser fruto de uma má-interpretação dos dados colhidos por PARRY e LORD, pois dá muita ênfase a processos mnemônicos. No entanto, para seu argumento, é importante que exista um estágio reprodutivo no qual é possível a passagem de um texto, no caso um poema composto em uma extensão monumental, que atingiu tal fama que poderia impor uma recitação palavra por palavra por um período de cerca de 6 gerações $^{6}$ (cf. KIRK, 1960b), para o caso da tradição depois de Homero. KIRK (1965) vê nesse tipo de recitação, que também é a dos bardos iugoslavos, senão uma reconstituição fiel palavra por palavra, variações somente negligenciáveis, uma constatação que é por si só absolutamente questionável. Na pior das hipóteses, esses bardos claramente inferiores ao gênio homérico, segundo KIRK (1965), somente repetem fórmulas e temas decorados, que foram aprendidos nas canções que escutam uns dos outros e os reelaboram de acordo com as canções que pretendem cantar.

Para justificar seus argumentos, KIRK (1965) usa as entrevistas realizadas por PARRY e LORD com esses bardos, os quais sempre afirmam ter aprendido seus poemas de outros poetas/cantores. Para sua justificativa, o autor simplesmente ignora, ou não compreende a argumentação de LORD, na qual aponta para as já referidas noções principais do que seriam os pontos centrais de um determinado poema, se suas palavras fixas ou sua essência.

No pensamento de KIRK (1965), Homero, ou o poeta criador da Ilíada, pois considera que a Odisséia seja de um outro poeta, é um gênio criador incomparável. Ele não teria aprendido seus cantos de outros cantores, mas sim composto uma obra monumental baseada na tradição. KIRK (1965) não vê nenhuma necessidade de utilização da escrita na composição, nem na difusão dos poemas homéricos. Para ele, o período criativo teve seu fim em Homero, e a partir daí, no período recitativo a grande meta era a manutenção literal dos textos consagrados. E é claro, como o gênio criativo de Homero era superior, também eram superiores as habilidades dos seus seguidores como recitadores, e as diferenças introduzidas nos poemas posteriormente seriam ainda mais negligenciáveis do que as que surgem na tradição iugoslava.

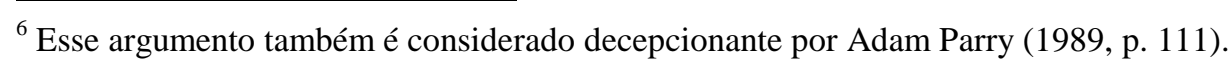


É claro que mesmo assim aconteceram adições e interpolações. KIRK (1965) acredita ser possível localizar, datar e explicar tais interpolações, em geral frutos de intervenções rapsódicas.

Um outro aspecto da obra de KIRK (1965) é a sua abordagem histórica. O autor tenta apresentar um contexto micênico, no qual a tradição teria se originado, tendo como base uma série de eventos em momentos diferentes da era do bronze, e que são comprimidos em 3 ou 4 gerações heróicas na poesia (cf. KIRK, 1965, p. 43). Apesar dessa credulidade inicial, KIRK (1965) acaba por aceitar, como SNODGRASS (1974), que os poemas apresentam uma mistura de elementos, o que seria natural de se esperar de uma longa tradição oral ${ }^{7}$. Esses elementos são provenientes de contextos históricos diferentes, absorvidos pela tradição em momentos também diferentes, que abrangem desde o esplendor micênico dos séculos XVIXIV a.C., passando por sua queda, pela chamada Idade Obscura (dark age) e culminando no século VIII a.C., no qual a composição monumental dos poemas teria ocorrido. A mistura lingüística, própria da língua homérica, é mais um indício de sobrevivência de tempos e contextos diferentes.

Como argumento para a datação da composição para esse período, KIRK (1965) utiliza a popularização de temas do ciclo épico na iconografia presente na cerâmica, bem como o surgimento de cultos a heróis por volta de 680 a.C. A utilização por poetas líricos de vocabulário épico seria outro indício da popularidade já no século VII das obras homéricas (cf. KIRK, 1965, p. 61). Para ele, o fato de a tradição oral demonstrar declínio após essa data é outro fator. A poesia do século VII, a escrita, principalmente, apresenta um tom individual e pessoal, o que torna a anonimalidade do aedo obsoleta. KIRK (1965) apresenta inúmeros outros argumentos para essa datação que, em função da extensão desses argumentos, serão somente remetidos a seu livro (parte VII). Por fim, reconhece que seus critérios de datação são pouco precisos, mas sugere uma data entre 800 e 700 a.C. como sendo mais provável para a composição monumental.

Para KIRK (1965), a transmissão após esse período não é exata, mas atinge uma grande precisão, como já foi dito. Esse seu argumento não é muito claramente exposto. Em geral, ele não aceita a teoria de um Homero letrado, algo proposto principalmente por BOWRA (1952), e que não será em pormenores explicitada aqui, tampouco a teoria de os textos terem sido ditados, proposta por LORD (1960 e 1991).

\footnotetext{
${ }^{7}$ As implicações dessa constatação para a interpretação de ambos, no entanto, são fundamentalmente diferentes.
} 
Mais recentes são os estudos de Gregory Nagy (1996) no livro Homeric Questions. Ele propõe um quadro evolutivo um pouco diferente do de KIRK, talvez não tão artificial, mas que apresenta algumas convergências. Ao iniciar suas considerações a respeito da tradição, NAGY (1996) propõe uma observação de método, pela qual afirma que, quando uma tradição pode ser percebida em termos absolutos dentro de uma sociedade, ela pode ser analisada em termos relativos por um observador de fora, que utiliza critérios empíricos. O que pode parecer antigo e imutável para um membro de uma sociedade pode ser contemporâneo e estar sempre mudando, do ponto de vista do empirista. A tradição não é apenas um sistema herdado, pois ela vem à vida no dia-a-dia de pessoas reais em situações reais (cf. NAGY, 1996, p. 15).

NAGY (1996) critica a possibilidade de os poemas mostrarem, de maneira simplista, um mundo, ou uma visão de mundo, que seria o construto de um ou mais homens de um ou mais contextos históricos. Para ele, os poemas homéricos requerem análises tanto diacrônicas quanto sincrônicas (cf. NAGY, 1996, p. 20). Esta análise comportaria, para além do simples texto, também a performance. A própria figura de Homero é um fato que exige reflexão. Os gregos tinham como costume apontar heróis culturais para suas grandes realizações. Homero seria este herói mítico para o caso da poesia. Para NAGY (1996), a super-personalização do termo "Homero", para além de uma utilização convencional, é perigosa. A poesia oral permite unidade e estrutura, o que de certa forma faz com que a presença necessária de um gênio criador não seja um pré-requisito básico para a composição dos poemas homéricos. Unidade e estrutura seriam o efeito de algo tradicional, ao invés de ser a causa de algo não tradicional (cf. NAGY 1996, p. 27).

A produção dos poemas é marcada por três aspectos interativos: a composição, performance e a difusão. NAGY (1996) concentra-se nos problemas da difusão, pois essa é uma imposição da necessidade de reconciliar as idéias da composição em performance com a realidade histórica de um texto relativamente integral e unificado. Como KIRK (1965), NAGY (1996) afirma não existirem provas de que a tecnologia da escrita seja necessária para a composição ou performance dos poemas homéricos. Ele também relativiza a utilização da escrita na difusão.

O problema da teoria de LORD (1960 e 1991) de que os textos teriam sido ditados esbarra, segundo NAGY (1996), na improbabilidade de que uma tradição manuscrítica pudesse sobreviver em um contexto tão recuado, para poemas que teoricamente atingiram uma abrangência grande por todo o mar Egeu (cf. NAGY, 1996, p. 32). Esse tipo de tecnologia em larga escala ainda não estava disponível. Ele também vê problemas na teoria de 
que estes manuscritos iniciais teriam ficado em posse de uma guilda que passava a simplesmente recitar os textos estabelecidos. As pesquisas do próprio LORD (1960) mostram que a presença de textos escritos e coletados dentro de tradições orais vivas não necessariamente interferem no processo de performance, pois não são necessários para a composição. NAGY (1996) não consegue compreender como um texto ditado teria influência em outras performances. $\mathrm{O}$ ato de escrever uma poesia oral não congela o processo de recomposição em performance (cf. NAGY, 1996, p. 68).

Tanto NAGY (1996) quanto KIRK (1965) colocam sérias dúvidas à própria possibilidade da escrita dos poemas em tão recuada data em função de uma inferência negativa acerca das condições materiais, que não seriam suficientes para tal empreendimento. Não é uma posição que Adam Parry (1989) parece disposto a aceitar. Para ele também não existem provas de que tal empreendimento fosse impossível. Algo assim poderia ter acontecido, sendo nada mais que um evento e um esforço notável, monumental, como a própria poesia homérica (cf. NAGY, 1989, p. 10).

De volta a NAGY (1996, p. 39), esse autor explica a difusão muito antiga dos poemas homéricos como sendo um reflexo de um processo de pan-helenismo, já debatido por SNODGRASS (1980). No modelo de NAGY (1996), quanto maior a difusão de uma canção, menores são as oportunidades de recomposição, típicas da poesia oral. Com esse processo, as versões cantadas passam a ter a maior aderência possível a uma versão teoricamente normativa e unificada. Um texto, termo compreendido em um sentido metafórico, se torna cada vez menos modificável no curso da difusão. Isso não implica, no entanto, o fim completo da recomposição, pois enquanto a tradição oral estiver viva isso ocorrerá, mas em escala reduzida.

Neste ponto, a argumentação de NAGY (1996) aproxima-se da de KIRK (1965), mas o teor das afirmações é de outra natureza. Ele compreende mais profundamente não só o valor das pesquisas de campo, mas também o processo de composição oral, que não é puramente mnemônico. Em seu próprio quadro evolutivo, o que NAGY (1996) indica é que a sucessão de estágios de difusão dos poemas homéricos demonstra progressivamente menos fluidez e mais rigidez.

O período originativo, meados do segundo milênio até o século VIII, seria mais fluido, no qual não existiam textos escritos. Um período formativo, ou pan-helênico, ainda sem textos escritos, iria de meados do século VIII a.C ao meio do século VI a.C. Um período 
definidor, centralizado em Atenas ${ }^{8}$, com a possibilidade da existência de textos escritos, no sentido de serem transcritos, iria de meados do século VI a.C. ao fim do século IV a.C. Um período de padronização iria do fim do século IV a.C. até o meio do século II a.C. Por fim, nos séculos posteriores, um período mais rígido, no qual a presença dos editores Alexandrinos marca a existência já certificada de uma tradição verdadeiramente manuscrítica que lida com textos completos (cf. NAGY, 1996, p. 42).

Para NAGY (1996, p. 104), o fato de que a poesia homérica era inicialmente apresentada oralmente, e o continuou sendo por todo o período clássico e além, é um dado histórico básico que não deve ser negligenciado. A textualização para esse autor não é necessariamente um evento, pois ele a entende como processo. E esse processo não depende necessariamente da escrita.

Não é algo com que James A. Notopoulos (1964) concorda. Para ele, existia na Grécia Arcaica um forte impulso de imortalizar grandes nomes e feitos por meio de epigramas e monumentos. Tal fato poderia ter influenciado a fixação pela escrita dos cantos tradicionais épicos, que teriam sido ditados para que fossem preservados após a passagem dos bardos itinerantes (cf. NOTOPOULOS, 1964, p. 24). Essa tradição compreendida por NOTOPOULOS (1964) não é baseada somente em Homero. Esse autor defende a independência dos poemas do chamado ciclo épico em relação aos poemas homéricos, dizendo não se tratar de uma situação heliocêntrica, na qual outros poemas orbitavam em torno da Ilíada e da Odisséia. O que acontecia é que todos esses poemas faziam parte de uma mesma tradição. Independentemente de outros poetas terem ouvido os cantos homéricos, o efeito seria semelhante ao descrito por LORD (1960) entre os iugoslavos (cf. NOTOPOULOS, 1964, p. 37). É muito difícil distinguir o mais antigo do mais recente no interior de uma tradição oral.

Algumas linhas merecem ser dedicadas também a Eric Havelock (1996), principalmente no que concerne à maneira como esse autor entende a tradição. Para ele, a possibilidade de criação do bardo é muito limitada, tendo em vista a maneira como está preso à tradição (cf. 1996, p. 105). E, nesse caso, HAVELOCK (1996) encontra-se muito próximo da opinião de Adam Parry (1989), pela qual o caráter formular da linguagem de Homero mostra um mundo onde tudo é de certa forma regulado, sendo assim apresentado como todos os homens comumente o percebem (cf. PARRY, 1989, p. 3). HAVELOCK (1996) entende os poemas homéricos como apresentando uma visão enciclopédica do mundo. Nesses poemas,

\footnotetext{
${ }^{8}$ NAGY (1996) faz referências às Panatenâicas e às competições de rapsodos.
} 
estariam inseridos uma aceitação integral dos valores morais da sociedade, assim como uma familiaridade com suas formas de pensamento e um apreço por elas (cf. HAVELOCK, 1996, p. 106). A narrativa homérica estaria em contato contínuo com a organização social geral (cf. HAVELOCK, 1996, p. 108). E para que esse enunciado "útil” de Homero seja histórico, técnico e moral, subsistindo em uma forma mais ou menos padronizada, é necessário que esteja na memória viva dos membros que compõem o grupo cultural. O papel do poeta é, portanto, o de recordar.

Os poemas homéricos apresentam um código geral de comportamento, cujas partes são mostradas nas centenas de contextos e variantes verbais. Portanto, essa poesia celebrava e conservava a organização social e o mecanismo administrativo, além da educação para a liderança e o controle pelas classes mais elevadas ${ }^{9}$. É bem verdade que HAVELOCK (1996) utiliza seus argumentos como parte de um estudo mais amplo, no qual tenta estabelecer características que diferenciem o que seria uma cultura grega e um modo de pensamento oral, do que se tornaria posteriormente uma cultura grega e um modo de pensamento escrito. Tal argumento encontrou pouco respaldo e aceitação entre os estudiosos (cf. HALVERSON, 1992, p. 148), mas isso não é impedimento para a utilização da interpretação de HAVELOCK (1996) acerca de como funcionava e de como seria transmitida esta tradição.

E nessa tradição compreendida por HAVELOCK (1996), passado e presente se intercomunicam quando o veículo de registro é a palavra formular, mantida na memória viva. É impossível, para ele, uma percepção do tempo histórico. Nesse contexto, bardos criativos e rapsodos eram contemporâneos e indissociáveis, uma vez que o que realmente importava era a repetição de normas, e não uma criação original. A poesia nessa era pré-alfabética não seria nem literatura nem arte, mas sim uma necessidade política e social, uma enciclopédia mantida por um esforço cooperativo (cf. HAVELOCK, 1996, p. 142-143). Homero, ao invés de ser especialmente original, concretiza a disposição mental dominante (cf. HAVELOCK, 1996, p. 154).

Uma vez apresentadas as idéias de inúmeros estudiosos, desde os anos 30 aos anos 90, acerca da natureza dos poemas homéricos, fazem-se necessárias, por fim, algumas considerações acerca da utilização desses poemas como fontes históricas. Se um elemento pode ser destacado como sendo evidente, após a leitura de tantos clássicos, é que não existem

\footnotetext{
${ }^{9}$ HAVELOCK (1963) também critica a comparação com a poesia balcânica, em geral por também considerar que a diferença de contexto é muito grande. Uma é campesina, a outra seria feita para uma elite governante, uma é marginal, a outra seria dominante, sendo o único meio de comunicação importante e significativo (cf. HAVELOCK,1963, p. 111). LORD (1991) responde a críticas desse tipo no seu último livro publicado em vida (LORD, 1991, p. 2 e p. 93-95).
} 
nem certezas absolutas, nem consenso no que se refere à composição e à difusão dos poemas homéricos. Ora, nenhuma resposta às questões inicialmente levantadas na abertura deste trabalho pode assim, no presente estágio, ser definitiva e inequívoca.

Não obstante, a utilização dos poemas como fonte histórica requer um pouco de reflexão. A princípio, poder-se-ia pensar, como ainda vem sendo feito, que os poemas retratariam alguma sociedade histórica real, sendo assim válidos como fontes históricas dessa sociedade. A dificuldade está em conseguir comprovar a relação inequívoca dos poemas com um contexto único e específico. O que ficou demonstrado é que os poemas, em função de sua própria mecânica de composição, apresentam uma verdadeira miscelânea de elementos, podendo ser datados de um número grande de contextos históricos diferentes, agregados a uma tradição e difundidos para gerações futuras.

A crítica de SNODGRASS (1974) a uma sociedade homérica histórica é de muito relevância. A mistura presente em Homero apresenta uma conjunção artificial de práticas históricas e elementos de vários períodos diferentes. Para SNODGRASS (1974), um poeta tradicional aceita as lições de seus predecessores, sendo estes muitos, e de mais de um período diferente, pois trata-se de uma longa tradição. Uma primeira mistura se dá nesse processo. No entanto, o poeta também admite elementos de sua própria experiência, e além disso, de sua própria imaginação. O resultado é uma colagem entre características puramente fictícias e elementos pontuais referentes a contextos históricos variados.

A crítica de SNODGRASS (1974), portanto, tenta demonstrar que uma equivalência direta dos poemas homéricos com qualquer período histórico específico, tal como FINLEY (1982) tentou realizar em relação ao período grego conhecido como Idade Obscura, tende a fracassar, por negligenciar os fatores acima enunciados. SNODGRASS (1974) não aceita a possibilidade de detectar determinados elementos individuais, e por meio do auxílio da arqueologia, antropologia comparativa e lingüística, fontes externas aos poemas, demonstrar a qual período possam pertencer. De maneira geral, uma equivalência direta da sociedade homérica com alguma sociedade histórica específica é rechaçada por esse autor.

Mas uma outra proposta pode ser apresentada. A despeito das intenções de um poeta retratar um tempo passado heróico, e da mecânica própria da composição, que implica uma linguagem tradicional que agrega elementos de mais de um período histórico, uma fonte histórica é válida para o período em que foi produzida. Essa seria uma regra de ouro do método histórico ${ }^{10}$. De maneira geral, essa proposta se diferencia fundamentalmente da de

10 “[...] uma fonte, qualquer que seja, deve ser inicialmente recolocada no seu contexto de produção." (TRABULSI, 2001 p. 22). 
SNODGRASS (1974). A busca seria concentrada para encontrar elementos referentes a um único período, o da composição dos poemas que, teoricamente, teria mais forças e seria mais presente nos poemas, e compará-lo a evidências externas que o relacionem a esse período determinado.

O problema com essa proposição está justamente na aceitação como dado de que o texto atual é, se não um equivalente perfeito ao "texto" composto, uma versão que apresenta somente variações negligenciáveis. Ian Morris, no artigo The use and abuse of Homer, de 1986, por exemplo, termina sua argumentação com a constatação de que ele não vê nenhuma razão para duvidar da conclusão de que a sociedade homérica é derivada do mundo real no qual Homero e sua audiência viveram. Nesse artigo, o autor tece críticas tanto para a posição de FINLEY (1982) acerca da interpretação dos poemas como fontes para os século X e IX a.C., quanto para a de SNODGRASS (1974), de que o relato homérico é essencialmente uma mistura, no que se refere aos períodos históricos. É bem verdade que a natureza do texto não foi uma das preocupações de MORRIS (1986). Salvo algumas breves considerações acerca de um aspecto da mecânica da poesia oral, seu texto não discute uma data de composição e de fixação para os poemas com os quais trabalha, nem muito menos como se deu sua difusão. Ele assume ser o século VIII a data da composição, sem explicar convincentemente a razão. Nesse sentido a crítica de WEST (1995) é muito válida. Para este autor, aqueles que apontam uma datação para o século VIII a.C., somente defendem esta posição porque a maioria dos estudiosos fazem o mesmo (cf. WEST, 1995, p. 203). Foram levados a acreditar que esta opinião amplamente aceita era a correta.

Essa aceitação não condiz com o estudo atual das pesquisas acerca do tema. O número relativamente reduzido de autores trabalhados aqui mostra que não há, em primeiro lugar, consenso no que se refere à data de composição dos poemas, e nem são aceitos critérios inequívocos de datação. Além disso, a composição não necessariamente envolve uma imediata fixação dos textos como documentos escritos. Adam Parry (1989) cita LESKY, ao dizer que a Questão Homérica dos nossos tempos é a relação entre as condições de composição oral e nossos textos escritos da Ilíada e da Odisséia (LESKY apud PARRY, 1989, p. 104). Uma série de sugestões são feitas por estes estudiosos para tentar reconciliar essa situação na qual as técnicas de composição que prescindem da escrita e a realidade histórica de um texto relativamente fixado estão em desacordo.

Critérios estilísticos e lingüísticos que tentam datar a fixação mais antiga ou tardia de trechos individuais também não recebem uma aceitação geral. Citando mais uma vez Adam Parry (1989), é válido questionar quão elástico é o próprio conceito do que é a Ilíada. Se 
existem variações que surgem em função de inúmeros processos (composição oral tradicional, difusão oral e escrita), qual seria o ponto em que um estudioso estaria autorizado a pensar que o texto em seu estágio presente não mais representa a Ilíada? A definição que ele faz deste poema não deixa de ser interessante, e tem implicações para a sequiência do presente argumento: a Ilíada é na verdade um longo poema que lida criticamente com uma concepção heróica da vida (cf. PARRY, 1989, p. 115-117) ${ }^{11}$.

Como fica, portanto, o historiador que deseja, qualquer que seja o motivo, trabalhar com os poemas homéricos como fonte histórica? É óbvio que qualquer uma das possibilidades criticadas acima pode ser adotada, se uma série de pressupostos forem aceitos. Qualquer pesquisa parte, de fato, de uma série de pressupostos. O problema fica evidente quando os pressupostos tomados estão no interior de polêmicas enormes, de maneira nenhuma resolvidas. E nem sempre as pesquisas demonstram claramente quais são seus pressupostos, deixando a questão implicitamente entendida, como se fosse tão óbvia que dispensa qualquer comentário.

Ora, os parâmetros pelos quais uma pesquisa se desenvolve devem ser deixados claros. Por isso, a proposta de mais uma maneira de como os poemas históricos podem ser trabalhados como fontes históricas será agora apresentada, tentando deixar claro quais são os pressupostos assumidos. Em primeiro lugar, podem ser encontrados entre os estudiosos aqui trabalhados elementos que são menos polêmicos, ou ao menos amplamente aceitos. Por exemplo, a questão da oralidade é um desses elementos. Outro ponto muito difundido, sendo na verdade um pressuposto básico da argumentação de todos eles, é a tradição. A maneira como essa tradição é descrita, e a mecânica teórica de seu funcionamento, podem ser de muita utilidade para a análise histórica.

A noção de tradição com a qual esses autores trabalham envolve a idéia de uma transmissão oral de lendas e estórias dentro de uma linguagem extremamente regrada, que agrega uma infinidade de elementos ajuntados no decorrer dessa transmissão, de geração para geração. A definição de LORD (1995), em seu livro publicado postumamente, é particularmente interessante. No que concerne às canções épicas, a tradição consiste, para o cantor individual, em todas as performances de todas as canções, de todos os cantores que ele já ouviu (cf. LORD, 1995, p. 3). A tradição é dinâmica, e persiste enquanto existirem cantores e ouvintes. Se em The singer of tales LORD (1960) dá muita ênfase ao aspecto do entretenimento, aqui ele aponta que a épica oral não é só uma forma de diversão, mas tem

\footnotetext{
${ }^{11}$ Esse autor também detecta uma unidade nos eventos descritos que implicaria algum tipo de planejamento.
} 
uma função séria para a sociedade na qual existe. Ela contém os valores dessa sociedade, bem como suas preocupações com os problemas básicos da comunidade e dos indivíduos (cf. LORD, 1995, p. 12). Esse tipo de tradição apresenta problemas significativos, sejam eles de moralidade ou do contrato legal básico que mantém o grupo junto e o faz funcionar. $\mathrm{Na}$ tradição estão dramatizadas as ansiedades fundamentais e as necessidades de sua cultura (cf. LORD, 1995, p. 13).

Se a análise lingüística demonstra a permanência e a convivência de termos que foram sendo incorporados a essa linguagem tradicional, seria possível que valores morais fossem também incorporados no interior das canções e transmitidos e reinterpretados para as gerações posteriores? Os poemas homéricos seriam veículos de valores morais no interior das comunidades. Os valores heróicos podem ser observados por toda a extensão dos poemas. Estaria retratada neles uma sociedade ideal, permeada por valores ideais, que seriam transmitidos e reinterpretados de geração para geração ${ }^{12}$. Não seria esse, por si só, um fato histórico que requer a atenção de um historiador?

Os textos homéricos sendo aceitos, portanto, como documentos válidos para uma visão particular acerca dessa tradição, poderiam ser trabalhados no interior de sua própria economia, e uma análise interna do texto teria validade para a história assim como tem para um estudo de natureza literária. A validade dos elementos ideais evidenciados por essas fontes seria relativa para a tradição como um todo. É verdade, no entanto, que seria mais ajustada para o período em que a composição e a fixação dos poemas teriam se dado. Nesse caso, em nome da precisão, a tentativa de apontar um período aproximado para esses fenômenos é justificada, mas as dificuldades são evidentes. Além daquelas envolvendo os processos de datação, talvez a própria noção de uma composição original seja complicada. Mesmo não sendo possível uma datação que apresente critérios inequívocos, a validade histórica ainda se mantém, a despeito da indefinição. Poderia se pensar em reatualizações dos valores ideais, em diferentes momentos, uma espécie de reconstrução histórica de um texto relativamente estável. Neste caso, a indefinição seria parte da validade histórica dessas fontes.

Por isso, alguns procedimentos de como o historiador pode trabalhar com elas passam a ser listados. Em primeiro lugar, vem a aceitação da sua validade relativa para a tradição como um todo. A linguagem poética tradicional agrega elementos do passado e abarca

\footnotetext{
${ }^{12}$ Existem, como não poderia deixar de ser, aqueles que não consideram esse tipo de transmissão como válido para os textos homéricos, criticando HAVELOCK (1996) e JAEGER (2001), como o faz HAINSWORTH (1970).
} 
também aspectos do presente do poeta, que opera reinterpretações. O ideal representado, portanto, não é imutável.

As fontes seriam particularmente válidas para os momentos em que ainda pode ser indicada uma grande vitalidade da tradição oral. É verdade que existe pouca certeza nesse aspecto. NOTOPOULOS (1964) sugere que a tradição se manteve viva e forte até o início do século V a.C. KIRK (1965) considera que a tradição de composição oral épica entrou em declínio logo após Homero, por volta do século VIII a.C. NAGY (1996) considera relevante que os poemas homéricos tenham sido apresentados oralmente no período clássico e além.

O próprio fato de a figura de Homero ser relacionada aos poemas é relevante. A tradição específica acerca desse nome pode ser datada, mas a análise de WEST (1999) mostra que o nome Homero só passou a ser realmente usado para denominar o autor dos poemas no fim do século VI a.C.

Apesar de a tradição ser brilhante e extremamente complexa, a composição em si pode ter sido realizada por um poeta, seja o próprio Homero ou algum outro ${ }^{13}$. Fica reconhecido também um certo nível de unidade. Segundo a interpretação de vários autores, esse tipo de unidade é possível na poesia oral e pode ser alcançado em uma única composição em performance, por um único poeta/cantor, ou como quer NAGY (1996), pela difusão no decorrer da tradição.

Por fim, considerações acerca da fixação do texto, seja como processo, como sugere NAGY (1996), seja como evento, como sugere LORD (1960 e 1991), podem trazer frutos. Mas uma datação que pode ser mais interessante, ainda que bem menos precisa, é a que mostra o interesse pelos temas épicos na iconografia (LOWENSTAM, 1997) ${ }^{14}$ e nos cultos aos heróis do ciclo épico (COLDSTREAM, 1976) ${ }^{15}$, que aparecem já no século VII a.C. Uma vez que isso não comprova necessariamente a existência em circulação de uma versão da Ilíada ou da Odisséia que não fosse muito distinta da que existe atualmente, indica ao menos

\footnotetext{
13 Adam Parry avisa dos riscos de considerar os poemas homéricos como frutos puramente da tradição, sem a interferência de um poeta (cf. PARRY, 1989, p. 135). Esse autor sugere, como LORD (1960), que os poemas foram colocados em forma escrita no momento da composição, só discorda do método. Enquanto LORD (1960 e 1991) sugere que são textos ditados, PARRY (1989 p. 139) considera a possibilidade de um Homero letrado.

${ }^{14} \mathrm{O}$ autor desse artigo acha as evidências para a datação dos poemas no século VIII e VII a.C. muito tênues, e se eles foram compostos realmente nesse período não atingiram um status de autoridade, pelo menos no que se refere à influência que teriam nos artistas iconográficos. No entanto, a presença temática de eventos e personagens do ciclo épico já indica a presença, se não dos poemas tal como existem hoje, da tradição na qual estavam inseridos. Ver também SNODGRASS (2004).

${ }^{15}$ Este autor fala de culto a heróis já no fim do século VIII a.C.
} 
o interesse nos temas veiculados também pela poesia oral, e a força dessa tradição já nesse período.

Todos esses argumentos foram levantados com o intuito de justificar a utilização dos poemas homéricos como fonte histórica. É verdade que estão longe de proporem uma resposta definitiva, mas qualquer estudo de história que deseje se utilizar dessas fontes deve partir dessa tentativa de justificar a sua validade.

A mudança de enfoque proposta se dá, portanto, da seguinte forma: a busca passaria a ser não por uma sociedade que determinado elemento dos poemas possa sugerir, mas pela compreensão de como a sociedade e os eventos retratados nos poemas podem ser interpretados como veículos de determinados valores ideais. Tais valores são referentes às sociedades nas quais a tradição que transportava os poemas estava viva. Esse processo aceito como histórico, seria estudado por meio de uma análise interna dos textos homéricos, considerados fontes históricas na medida em que representam um estágio da tradição. As análises de PARRY e LORD mostram os poemas como tendo sido compostos em um sistema formular tradicional, algo que é em certa medida amplamente aceito.

A dificuldade, talvez tão grande quanto as encontradas por outras perspectivas de análise histórica, passa a ser a determinação de qual é o momento mais apropriado para a interpretação desses elementos ideais, no interior da tradição. Mas caso uma precisão deste tipo seja impossível de ser alcançada, reconhecer sua validade geral como veículo de ideais da tradição pode, por si só, trazer frutos.

\section{Referências}

BOWRA, C. M. Heroic Poetry. Londres: Macmillan \& Co. Ltd, 1952.

COLDSTREAM, J. N. Hero-cults in the age of Homer. Journal of Hellenic Studies, v. 96, p. 8-17, 1976.

FINLEY, M. I. O Mundo de Ulisses. Lisboa: Presença, 1982.

HAINSWORTH, J. B. The criticism of an oral Homer. Journal of Hellenic Studies, v. 90, p. 90-98, 1970.

HALVERSON, John. Havelock on Greek orality and literacy. Journal of the History of Ideas, v. 53, No.1, p. 148-163. Jan.-Mar., 1992.

HAVELOCK, Eric. Prefácio a Platão. Campinas: Papirus, 1996. 
JAEGER, Werner. Paidéia: A formação do Homem Grego. São Paulo: Martins Fontes, 2001. (4 edição).

KIRK, G. S. Objective dating criteria in Homer. Museum Helveticum, v. 17, p. 189-205, 1960a.

Homer and Modern Oral Poetry: Some Confusions. Classical Quarterly, v. 10, No. 2 , p. 271-281, Nov., 1960 b.

. The songs of Homer. Cambridge: Cambridge University Press, 1962.

Homer and the epic. Cambridge: Cambridge University Press, 1965.

LORD, Albert Bates. The singer of tales. Cambridge (Massachusetts): Harvard University Press, 1960.

. Epic singers and oral traditions. Nova Iorque: Cornell University Press, 1991.

. The singer resumes the tale. Nova Iorque: Cornell University Press, 1995.

LOWENSTAM, Steve. Talking Vases: The relationship between the Homeric poems and archaic representations of epic myth. Transactions of the American Philological Association (1974-), v. 127, p. 21-76, 1997.

MORRIS, Ian. The use and abuse of Homer. Classical Quarterly, v. 5, p.94-115, 1986.

NAGY, Gregory. Homeric Questions. Austin: University of Texas Press, 1996.

NOTOPOULOS, James A. Studies in early Greek oral poetry. Harvard Studies in Classical Philology, v. 68, p. 1-77, 1964.

PARRY, Adam. The language of Achilles and other papers. Oxford: Oxford University Press, 1989.

PARRY, Milman. Studies in the Epic Technique of Oral Verse-Making I. Homer and Homeric Style. Harvard Studies in Classical Philology, v. 41, p. 73-147, 1930.

Studies in the Epic Technique of Oral Verse-Making II. The Homeric Language as the Language of an Oral Poetry. Harvard Studies in Classical Philology, v. 43, p. 1-50, 1932.

. The making of the Homeric verse. Oxford: Oxford University Press, 1971.

SNODGRASS, A. M. An historical Homeric society? Journal of Hellenic Studies, v. 94, p. 114-125, 1974.

Archaic Greece: the age of experiment. Berkeley e Los Angeles: University of California Press, 1980. 
Homero e os Artistas: texto e pintura na arte grega antiga. São Paulo: Odysseus Editora, 2004.

TRABULSI, José Antonio Dabdab. Ensaio sobre a mobilização política na Grécia antiga. Belo Horizonte: Editora UFMG, 2001.

WEST, M. L. The date of the Iliad. Museum Helveticum, v. 52, p. 203-219. 1995.

. The invention of Homer. Classical Quarterly 49, v.2, p. 364-382. 1999. 